\title{
Structural changes driven by pulsed magnetic fields: comparison of off-stoichiometric CoNiGa and (CoNiCu)(AIGaIn) intermetallic compounds
}

\author{
Gregory GERSTEIN ${ }^{1}$, Georgiy FIRSTOV ${ }^{2}$, Tetiana KOSORUKOVA ${ }^{2}$, Yuri KOVAL ${ }^{2}$, Valeriy ODNOSUM ${ }^{2}$, \\ Andrej DALINGER ${ }^{1}$, Mathieu PASTUREL ${ }^{3}$, Hans Jürgen MAIER ${ }^{1}$ \\ ${ }^{1}$ Institut für Werkstoffkunde (Materials Science) Leibniz Universität Hannover, \\ An der Universität 2, 30823 Garbsen, Germany \\ ${ }^{2}$ G.V. Kurdyumov Institute for Metal Physics of the National Academy of Sciences of Ukraine, \\ Vernadsky Blvd. 36, 03680 Kyiv, Ukraine \\ ${ }^{3}$ ISCR/CSM, Université de Rennes 1, UMR-CNRS 6226, Campus de Beaulieu, \\ 263 Avenue du Général Leclerc, 35042 Rennes Cedex, France \\ * Corresponding author. Tel.: +49-0511 762-3907; fax: +49-0511 762-4352; e-mail: gerstein@iw.uni-hannover.de
}

Received October 15, 2019; accepted December 18, 2019; available on-line April 1, 2020

https://doi.org/10.30970/cma12.0388

Fine magnetic- and microstructures in CoNiGa magnetic shape memory alloy single crystals were generated by applying pulsed magnetic fields of up to $0.7 \mathrm{~T}$. The effects observed could be attributed to a change in the dynamics of the interaction process between the magnetic field and the microstructure of the offstoichiometric sample. This report addresses the impact of pulsed magnetic fields on the structure and phase composition in CoNiGa and multicomponent (CoNiCu)(AlGaIn) alloys. A pulsed magnetic field can result in different microstructural accommodation processes in stress-induced martensite, as compared to the application of mechanical stress or a permanent magnetic field. In a pulsed magnetic field the development of new nano-twin systems in the martensitic structure of the CoNiGa alloy and the formation of fine magnetic domains at the microscale, as well as the evolution of this process, in (CoNiCu)(AlGaIn), were observed. The ramifications of exploiting pulse magnetic fields for magnetic shape memory in these compounds will be discussed.

Ferromagnetic shape memory alloy / Multicomponent alloy / Twinning / Fatigue / Pulsed magnetic field

\section{Introduction}

The use of magnetic alloys with shape memory (MSMA) will significantly increase the frequency of response of a material. Control of the domain structure under the influence of a pulsed magnetic field allows reaching the desired high-frequency range of the operating mode of the actuator. The value of applied field power was first determined from the results published in [1-4], from which it follows that saturation of the magnetic field in CoNiGa alloys occurs at a magnetic field density from 0.2 to $0.6 \mathrm{~T}$, depending on the chemical composition of the alloy. According to the results of mechanical testing, the energy required to move the twin boundaries can be estimated from the stress-strain results of [5]. The uniaxial mechanical stress required for stress-induced twin-boundary motion in $\mathrm{Ni}_{48} \mathrm{Mn}_{30} \mathrm{Ga}$ samples does not exceed $2.5 \mathrm{MPa}$. This stress was determined as $\sigma_{\mathrm{tw}}=2 \mathrm{MPa}$ for the NiMnGa alloy and $\sigma_{\mathrm{tw}}=12-15 \mathrm{MPa}$ for CoNiGa [4]. Still [6], the internal friction of the structure (blocking stress), which must be overcome by the energy from the magnetic field, is as low as a few MPa, even for a perfect crystal. It has been shown [7] that, for a field strength of $8 \mathrm{kOe}$, the induced strain change is $0.2 \%$ on rotating the field from the [001] to the [110] direction. According to the authors of [7] this striking behavior is associated with a magnetic field-induced reorientation of twin-related martensitic variants and is at the origin of magnetic control of the shape-memory effect in this system. Coexistence of several twinned martensite variants was the main reason for the formation of the crack network leading to fracture in NiMnGa [8]. An attempt to control the magnetic shape memory by a pulsed magnetic field in $\mathrm{CoNiGa}$ resulted in some 
response, but fatigue effects duly appeared [9]. On the other hand, the multi-component $(\mathrm{CoNiCu})(\mathrm{AlGaIn})$ single-phase high-entropy intermetallic showed a triclinically distorted B2 structure similar to TiZrHfCoNiCu and underwent a B2 $\leftrightarrow \mathrm{L} 10$ martensitic transformation [10]. It was also found that these compounds exhibit magnetic properties (details of the magnetic studies will be published elsewhere). The use of the multi-component magnetic $(\mathrm{CoNiCu})(\mathrm{AlGaIn})$ complex intermetallic compound undergoing a martensitic transformation should increase the resistance of the material to functional fatigue, due to the significant increase in the mechanical properties that was observed in [10].

The present work is dedicated to the search for scenarios where, despite the high strength of multicomponent intermetallic compounds (compared to three-component $\mathrm{CoNiGa}$ ), it would be possible to control the martensite formation with the help of a pulsed magnetic field.

\section{Experimental}

The setup for applying a pulsed magnetic field (MF) has been described in [9]. For the compression tests on a universal testing machine, non-magnetic fixtures (Ti alloy) were manufactured. Furthermore, an active sample cooling and heating device (e.g. nitrogen gas and conductive heating) was provided (Fig. 1).

Suitable coils for a superimposed magnetic field, both parallel and perpendicular to the compressive stress axis, were designed and manufactured. The sample temperature was monitored by a thermocouple and the magnetic flux density measured with the conventional Gauss/Teslameter and a special Hall probe. Fig. 1 shows a schematic diagram of the experimental setup for a perpendicular (a) and parallel (b) alignment of the magnetic field and stress axis. For reasons of clarity, the variants are shown separately. Since a change of the magnetic field orientation is necessary for the pulse strategy shown in Fig. 2, a combined coil arrangement was used in practice.

Fig. 2 shows the course of the investigations of the influence of pulse-shaped magnetic fields on the magnetic field-induced strain (MFIS). The three magnetic field-time curves shown in Fig. 2 were considered for this purpose.

At first, the two parameters $H_{\max }$ (maximum magnetic field strength) and $\tau_{\text {pulse }}$ (pulse duration) were available as variables. Preliminary investigations showed that values of up to $40 \mathrm{kOe}$ can be achieved for $H_{\max }$, while the order of magnitude of $\tau_{\text {pulse }}$ lies in the range of $0.2 \mathrm{~ms}$. The investigation of the single pulse was intended to show the dependence of the maximum achievable MFIS on the two variables. In the second step pulse sequences (Fig. 2b) were considered. There are now two further variables: the time between two pulses $\tau_{\text {pause }}$ (order of magnitude $0.2-1 \mathrm{~s}$ ) and the number of pulses $n_{\text {pulse }}$. The optimal parameters from the results of the single-pulse observation were adopted and the dependence of the MFIS on the new parameters of the pulse strategy was determined. Finally, it was necessary to evaluate which positive effects a pulse sequence offers compared to a single pulse.

In the following, pulse sequences with alternating orientation of the magnetic field (from parallel to perpendicular to the mechanical stress axis and vice versa, see Fig. 2c) were used. For this purpose, the two coil arrangements in Fig. 1 were combined and the coils were switched alternately.

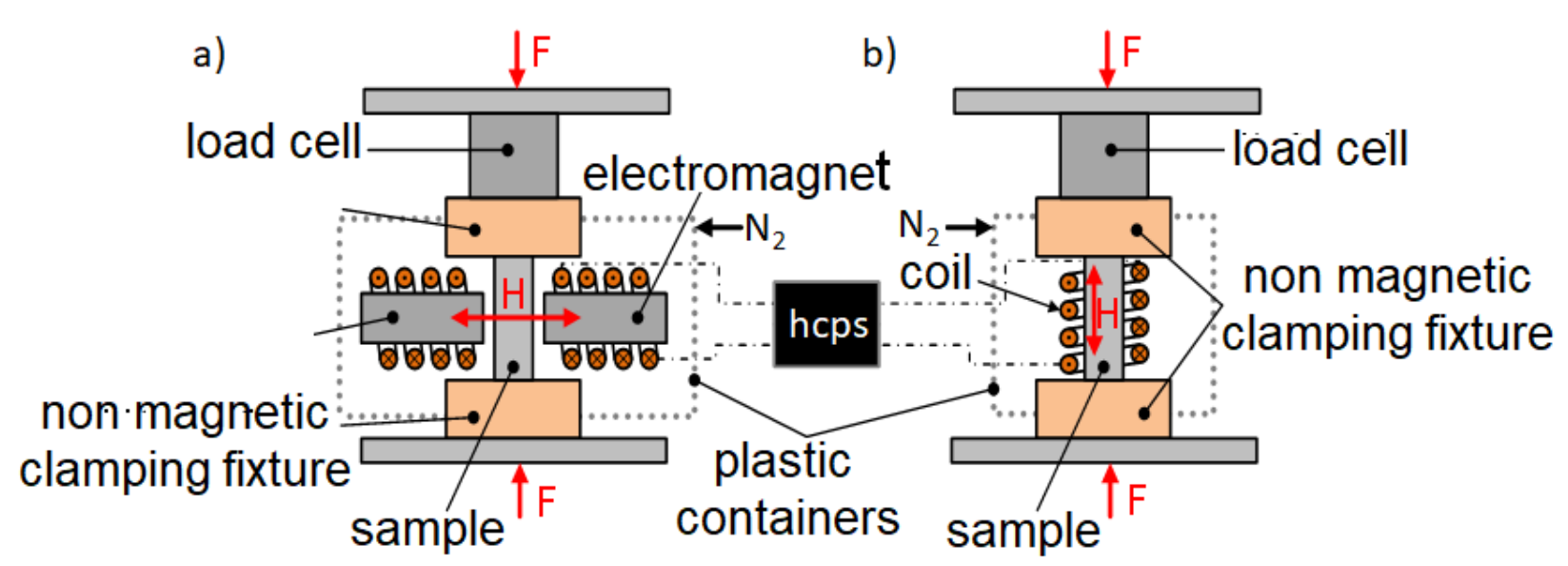

Fig. 1 Schematic presentation of the experimental arrangements for the generation of a) magnetic fields perpendicular to the mechanical stress axis; b) magnetic fields parallel to the mechanical stress axis; (hcps = high-current pulse system). 


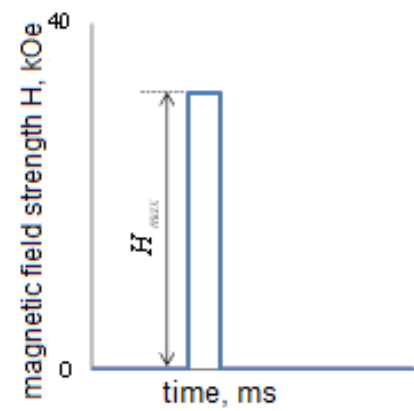

a)

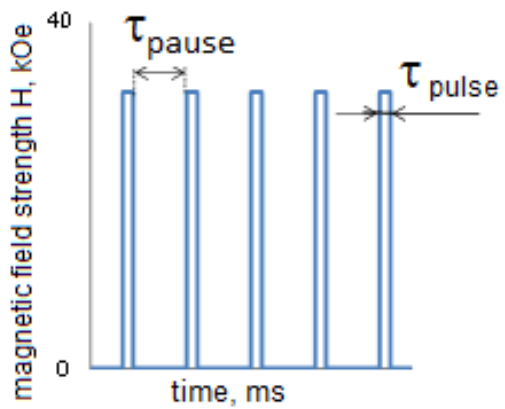

b)

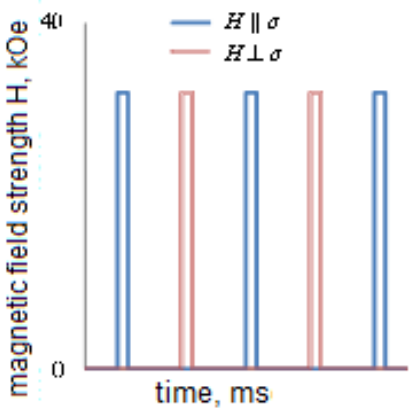

c)

Fig. 2 Possible flux density-time schemes: a) single pulse; b) pulse sequence; c) pulse sequence with change of orientation.

Experiments with $\mathrm{Co}_{49} \mathrm{Ni}_{21} \mathrm{Ga}_{30}$ single crystals and $\mathrm{Co}_{31.09} \mathrm{Ni}_{27.77} \mathrm{Cu}_{12.27} \mathrm{Al}_{12.48} \mathrm{Ga}_{15.44} \mathrm{In}_{0.95} \quad$ polycrystals were conducted using a special impulse magnetic driver, which has been described in detail earlier [9]. The test crystals had the dimensions $7.0 \times 1.7 \times 1.7 \mathrm{~mm}$. All the surfaces were mechanically polished down to $1 \mathrm{~mm}$ prior to testing. During the pulsed-field experiments, the sample was placed inside the coil. In the results presented below for the single crystal the applied magnetic field is always parallel to one of the $\{100\}$ planes. In our experiments on $\mathrm{Co}_{49} \mathrm{Ni}_{21} \mathrm{Ga}_{30}$ single crystals, a compressive load of $59.1 \mathrm{MPa}$ was applied, which is less than the stress corresponding to the $\sigma$-plateau of the $\mathrm{Co}_{49} \mathrm{Ni}_{21} \mathrm{Ga}_{30}$ alloy in stress-strain tests at room temperature [11]. In addition, a pulseshaped magnetic field was superimposed (Fig. 1a or 1b). The resulting change in shape due to the magnetic field-induced martensite orientation $\varepsilon_{1}$ is, as assumed according to [4], irreversible, i.e. also present after the magnetic field pulse. In order to make the shape change (partially) reversible, the orientation of the magnetic field with respect to the mechanical stress axis should be modified afterwards. The magnetic field pulse should be oriented along the soft magnetization axis $[110]_{\mathrm{M}}$ or $[110]_{\mathrm{P}}$ of the sample, according to our preliminary considerations. The resulting change in shape should then be $\varepsilon_{2}$, which is smaller than $\varepsilon_{1}$. Then a pulse-shaped magnetic field parallel to the stress axis can be superimposed again, closing the cycle.

For the analysis of functional fatigue, in both cases it was necessary to determine how the proportion of irreversible deformation $\varepsilon_{\text {irr }}$ behaves over progressive cycling. A comparison of the functional fatigue behavior of specimens with different compositions $\left(\mathrm{Co}_{49} \mathrm{Ni}_{21} \mathrm{Ga}_{30}\right.$ single crystals or $(\mathrm{CoNiCu})(\mathrm{AlGaIn})$ polycrystals) can show whether a positive influence on the functional properties is possible (analogous to NiTi alloys under cyclic stressstrain loading [12]).

\section{Results and discussion}

The stress-strain behaviors of the $\mathrm{Co}_{49} \mathrm{Ni}_{21} \mathrm{Ga}_{30}$ single crystal (stress-induced martensite formation) and the $\mathrm{Co}_{31.09} \mathrm{Ni}_{27.77} \mathrm{Cu}_{12.27} \mathrm{Al}_{12.48} \mathrm{Ga}_{15.44} \mathrm{In}_{0.95}$ poly-crystalline sample (stress-induced martensite formation accompanied by slip) are presented in Figs. 3a and 3b, respectively. Visualization of the stress-induced slip accompanying the martensite formation in the latter is presented in Figs. $3 \mathrm{c}$ and $3 \mathrm{~d}$.

The CoNiGa single crystal (Fig. 3a) shows martensite formation at a stress not higher than $100 \mathrm{MPa}$ and about $5 \%$ of martensite deformation. Further increase in stress resulted in significant strain hardening up $1400 \mathrm{MPa}$. In comparison, stressinduced martensitic transformation in $\mathrm{Ni}_{2} \mathrm{MnGa}$ single crystals exhibits only $4 \%$ of martensitic strain prior to further brittle fracture [13]. $(\mathrm{CoNiCu})(\mathrm{AlGaIn})$ shows a higher yield strength than CoNiGa, according to [10] and our present results confirm this (Fig. 3b). Yielding that involves a combination of martensite and plastic deformation (2\% altogether) starts seriously above $1200 \mathrm{MPa}$ and exhibits parabolic strain hardening (Fig. 3b), while in the case of the CoNiGa single crystal linear strain hardening takes place (Fig. 3a).

CoNiGa single crystals exhibit the formation of twinned martensite crystals (see [9] for example). In the case of the $(\mathrm{CoNiCu})(\mathrm{AlGaIn})$ polycrystal, martensitic crystals are formed simultaneously with a massive movement of dislocations (Fig. 3c). The latter can be clearly seen in Fig. 3d, which shows slip lines inside martensitic crystals. 
Fig. 4 shows optical observations of the evolution of the microstructure of the CoNiGa single crystal upon the application of a pulsed magnetic field (PMF). There is a change of the twin structure of the

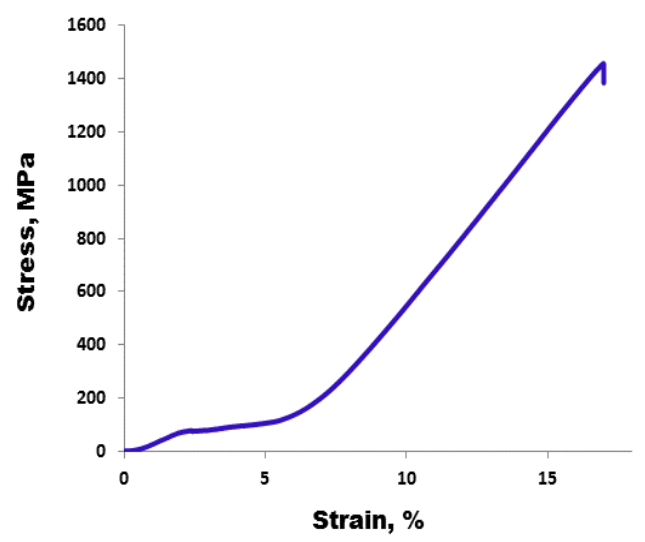

a)

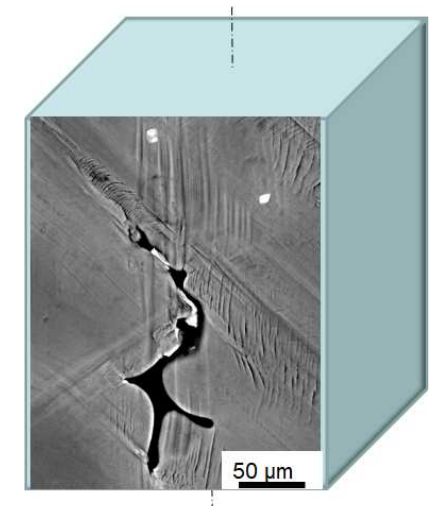

c) material (Fig. 4a-c) when, in addition to the larger twins observed after 5000 magnetic pulses of $0.3 \mathrm{~T}$, nano twins are formed after another 50000 magnetic pulses of $0.7 \mathrm{~T}$.

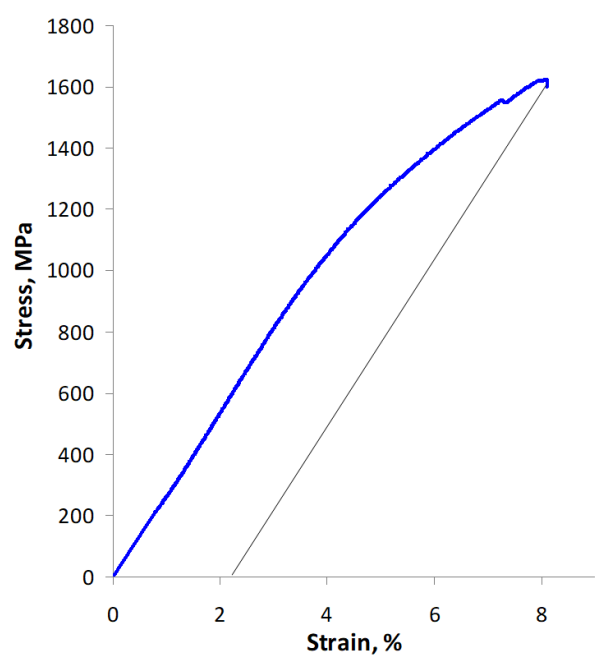

b)

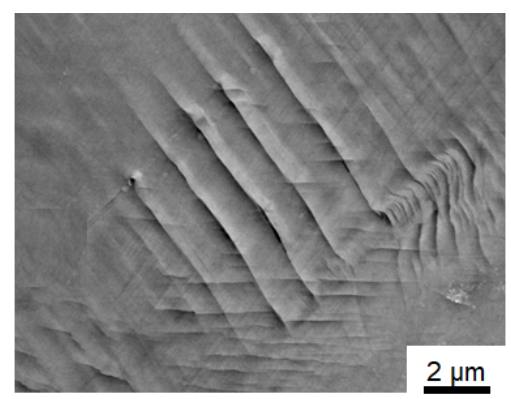

d)

Fig. 3 Stress-strain behavior at a) stress-induced martensite formation in the CoNiGa single crystal; b) stress-induced martensite formation accompanied by slip in the ( $\mathrm{CoNiCu})(\mathrm{AlGaIn})$ polycrystal, and optical microscopy for the latter c) after unloading from $1250 \mathrm{MPa}$; d) emphasizing single elements of sliding (slip lines).

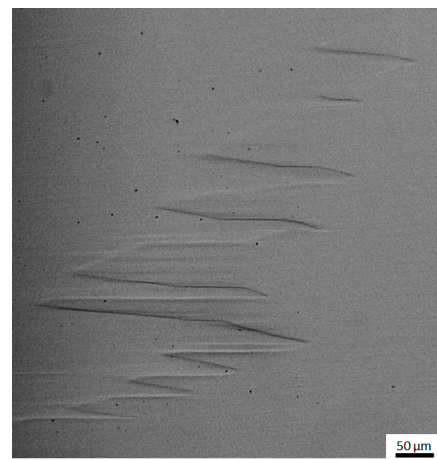

a)

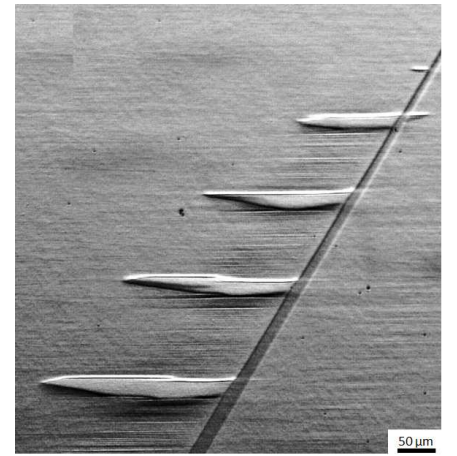

b)

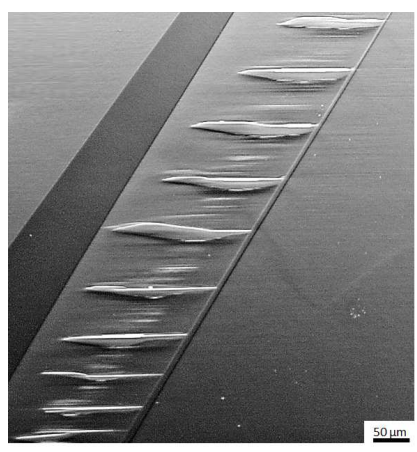

c)

Fig. 4 Optical microscopy detailing the change in the microstructure of a CoNiGa single crystal of a pre-loaded (-59.1 MPa) sample: a) initial microstructure containing twin variants; b) microstructure of the sample after 5000 magnetic pulses of $0.3 \mathrm{~T}$; c) microstructure of the sample after 50000 magnetic pulses of $0.7 \mathrm{~T}$. 


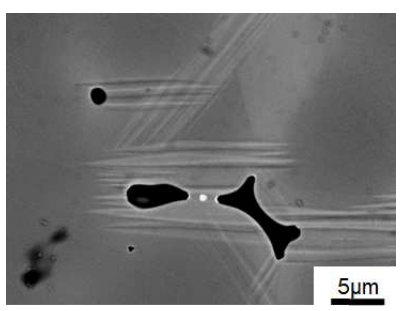

a)

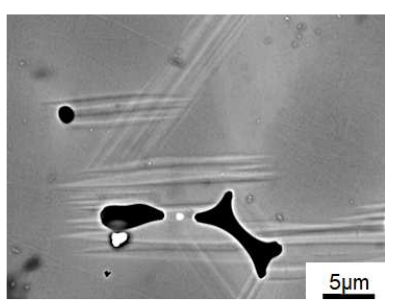

b)

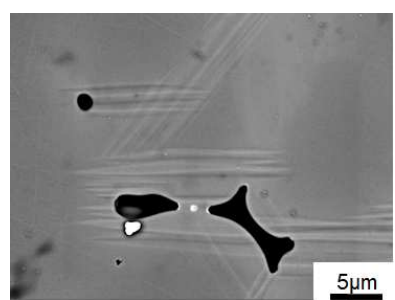

c)

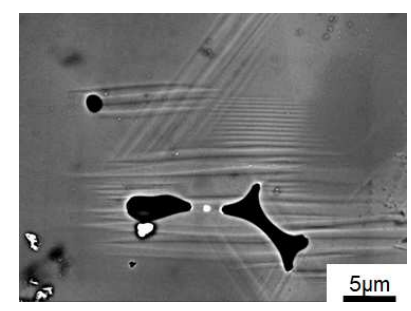

d)

Fig. 5 Changing of the martensitic structure in the $(\mathrm{CoNiCu})(\mathrm{AlGaIn})$ multicomponent intermetallic compound: a) as cast initial structure containing martensitic variants; b) after 10000 pulses in a of $0.7 \mathrm{~T}$; c) after additional 60000 pulses of $0.7 \mathrm{~T}$; d) after additional 10000 pulses of $0.7 \mathrm{~T}$, applied simultaneously with $300 \mathrm{MPa}$ external stress.

The development of different nano-twin systems under pulsed MF shows that, in contrast to previously described multi-variant changes of the martensitic structure in CoNiGa alloys [9], another variant of material fatigue in the structure is possible. This is the development of a nano-twin structure under the influence of a magnetic field and preliminary application of an external load. The size of the twins formed at load is not increased, while the number of nano twins inside the microtwins has increased (Figs. 4b and 4c).

Energetically, the possibility of such a variant of twin development results from the interaction of domains and twins considered in [14]. The magnetic domains start to nucleate at the surface. The surface undulation may assist the nucleation of domain walls. Magnetic domains accompanied by surface relief are the result of the accommodation of the internal strain and magnetic interactions between differently oriented twins, in order to reduce the internal energy. This mechanism leads to different metastable configurations during repeated magnetisation.

Fig. 5 shows the influence of PMF on the microstructure of the $(\mathrm{CoNiCu})(\mathrm{AlGaIn})$ multicomponent intermetallic compound. It is evident that the existing martensitic crystals formed in the ascast $(\mathrm{CoNiCu})(\mathrm{AlGaIn})$ multicomponent alloy are extremely stable to the application of a PMF alone. Even 70000 pulses is not enough to influence them in any way (Fig. 5a-c). When the pulses were applied simultaneously with an external stress of $300 \mathrm{MPa}$, there was a drastic growth of fine martensitic crystals without any signs of plastic deformation or, in other words, fatigue (Fig. 5d). Application of $300 \mathrm{MPa}$ alone did not result in any changes, as only common elasticity was observed (Fig. 3b). Increased stress resulted in the formation of martensite accompanied by dislocation slips above $1200 \mathrm{MPa}$. The influence of simultaneous PMF and stress allowed forming martensite in a highly distorted fashion, which resisted to any sort of shear in the $(\mathrm{CoNiCu})(\mathrm{AlGaIn})$ matrix. In other words, the easy movement of the martensite/twin boundaries in CoNiGa (Fig. 3a) followed by a certain fatigue [10], which was lost on the path to highly strengthened $(\mathrm{CoNiCu})(\mathrm{AlGaIn})$ (Fig. 3b), was reinstored by the simultaneous influence of PMF and stress below the yield strength. This indicates that such a combination leads to a possible reversibility of the magnetic shape memory effect, controlled by a pulsed magnetic field.

\section{Acknowledgements}

Financial support by the Deutsche Forschungsgemeinschaft (DFG) within the Project "Untersuchungen des Zusammenhangs zwischen Mikrostruktur und funktionaler Ermüdung in Hochentropie-Formgedächtnislegierungen" (Project No. 388671975, contract No. MA1175/79-1) is gratefully acknowledged.

\section{References}

[1] K. Oikawa, T. Ota, F. Gejima, T. Ohmori, R. Kainuma, K. Ishida, Mater. Trans., JIM 42 (2001) 2472-2475.

[2] J. Liu, H.X. Zheng, M.X. Xia, Y.L. Huang, J.G. Li, Scr. Mater. 52 (2005) 935-938.

[3] Y.X. Li, H.Y. Liu, F.B. Meng, L.Q. Yan, G.D. Liu, X.F. Dai, M. Zhang, Z.H. Liu, J.L. Chen, G.H. Wu, Appl. Phys. Lett. 84 (2004) 3594-3596.

[4] H. Morito, K. Oikawa, A. Fujita, K. Fukamichi, R. Kainuma, K. Ishida, J. Phys.: Condens. Matter 21 (2009) 256002.

[5] V.V. Kokorin, V.V. Martynov, Phys. Met. Metallogr. 723 (1991) 106.

[6] S. Fähler, Interfaces in Multiferroic Magnetic Shape Memory Alloys, Habilitation, LeibnizInstitut für Festkörper- und Werkstoffforschung (IFW), Dresden, 2014, 144 p.

[7] K. Ullako, J.K. Huang, C. Kantner, R.C. O'Handley, V.V. Kokorin, Appl. Phys. Lett. 69 (1996) 1966.

[8] F. Xiong, Y. Liu, E. Pagounis, J. Magn. Magn. Mater. 285 (2005) 410-416. 
G. Gerstein et al., Structural changes driven by pulsed magnetic fields: comparison of off-stoichiometric...

[9] G. Gerstein, G. Firstov, Y. Chumlyakov, P. Krooß, T. Niendorf, A. Dalinger, H.J. Maier, Mater. Sci. Technol. 34 (2018) 1954-1964.

[10] G. Gerstein, G.S. Firstov, T.A. Kosorukova, Y.N. Koval, H.J. Maier, Shape Mem. Superelasticity 4 (2018) 360-368.

[11] D. Niklasch, J. Dadda, H.J. Maier, J. Mater Sci. 43 (2008) 6890-6901.
[12] S.C. Weighardt, H.J. Maier, Y.I. Chumlyakov, J. Alloys Compd. 577 (2013) 219-221

[13] V.V. Kokorin, V.V. Martynov, V.A. Chernenko, Scr. Metall. Mater. 26 (1992) 175-177.

[14] Y. Ge, O. Heczko, O. Söderberg, S.-P. Hannula, Scr. Mater. 54 (2006) 2155-2160. 